ON A

\title{
DISEASE OF THE SKIN
}

\author{
PRODUCED BY THE
}

\section{ACARUS FOLLICULORUM,}

ILLUSTRATED BY CASES OBSERVED IN THE DOG,

BY

EDWARD SPARKS, M.A., M.B. Oxon., M.R.C.P., PHYBICIAN FOR DISEASES OF THE SKIN IN CHARING CROSS HOSPITAI, AND PHYSICIAN TO ST. GEORGE'S (HANOVER SQUARE) DISPENSARY.

COMMUNICATED BY

W. FAIRLIE CLARKE, F.R.C.S.

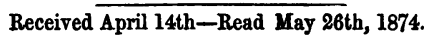

Since Gustav Simon discovered the Acarus folliculorum in 1841 (see 'Müller's Archiv') much has been written about the anatomy and even about the development of this curious creature by Simon, Professor Erasmus Wilson, and others, but it has been generally regarded up to the present time as a harmless denizen of the sebaceous glands and hair-follicles of the skin.

The only person who has really described a diseased condition of the skin due to its presence is Dr. Gruby, who was professor of anatony and histology in Paris in 1846, and who published his earlier observations in the 'Comptes Rendus,' March, 1845, and his later and more important ones in the 'Monthly Journal of the Medical Sciences,' (England) in November, 1846. Before, however, I speak 
of Gruby's researches in detail, or the evidence which I have to adduce in confirmation of them, it may be best to lay before you briefly the opinions of other writers on the subject which I have been able to collect up to the present time.

Simon, the discoverer of the Acarus ('Die Hautkrankheiten durch anatomische Untersuchung erläutert,' 2te Auflage, Berlin, 1851), speaks doubtfully on the question whether it can produce a disease of the skin, and says (S. 319) : "It is possible that the presence of the Acarus in very large numbers might give rise to comedones and acne pustules, though this cannot be decided for certain." Simon also questions the accuracy of Gruby's observations. Wedl ('Grundzüge der pathologischen Histologie,' Wien, 1854), S. 807, says: "The Acarus being unprovided with spines or bristles and living in the fat of the sebaceous glands produces no irritation in the skin, and could only if present in large numbers produce an irritation of the gland itself and the neighbouring tissues."

Professor Erasmus Wilson in his elaborate memoir on the Acarus or Entozoon folliculorum in the 'Philosophical Transactions' for 1841, p. 305, although he goes most minutely into the descriptive anatomy of the animal, has no reference to any disease occasioned by it; and in later editions of his work on diseases of the skin, e.g. the edition of 1868, p. 876, he says: The Steatozoon (acarus) would seem to give rise to no uncomfortable effects by its presence unless perchance it should multiply to such an extent as to become a source of irritation to the follicle." Mr. Wilson states that he "had only examined healthy people when he wrote, and had not had recourse to a skin affected with acne," and he does not allude to the possibility of its producing a disease in animals. Förster in his 'Lehrbuch der pathologischen Anatomie' (8te Auflage, 1868), says (S. 548): "The acarus (Haarsackmilbe) is always found accidentally (ein zufälliger Befund), and appears not to give rise to any alterations in the skin."

Professor Hebra, of Vienna, in the last German edition 
of his 'Lehrbuch der Hautkrankheiten,' 1872, S. 98, speaks as follows : "In my opinion the Acarus folliculorum can be regarded neither as the cause of comedones nor of an acne, because one is less often successful in extracting it from comedones or acne tubercles than from the follicles of persons with fine smooth skins, by scraping the skin with the back of a knife blade and examining the secretion which is thus squeezed out."

Lastly, Neumann, of Vienna (' Lehrbuch der Hautkrankheiten,' Dritte Auflage, 1873, S. 506), says decidedly : "The acari (folliculorum) have no further injurious influence on the skin (beyond occurring in it); according to Gruby they make the hairs fall out, which is a very improbable thing ("was sehr unwahrscheinlich ist.") Other English works on skin diseases beside Wilson's, as far as I know, merely allude to the acarus, en passant, and neither Hardy nor Bazin in France mention it at all, while Devergie merely quotes a passage from Gruby without expressing any independent opinion as to his facts. The larger number of authorities, therefore, are inclined to the belief that the acarus does not produce any skin disease at all either in man or animals, and the most recent writers, e.g. Hebra and Neumann, are the most positive of all of this, although apparently acquainted with the direct statements of Gruby, which have somehow failed to receive much credence either from his contemporaries or his successors. His writings have indeed been so nearly forgotten that it was with difficulty I succeeded in finding the reference to his original papers.

Dr. Gruby inoculated a " middle-sized" dog with the acari from man, and kept it under observation for two years. At the end of this time he states that "the animalcules have so increased as to occupy every follicle in his skin; he has lost all his hair, and the skin is as naked as that of an infant. The epidermis has been raised in various places, leaving the true skin exposed, and here and there considerable inflammation has been excited, causing scales of inspissated pus to form on the surface, and his general strength is now so reduced that he can scarcely 
move." In this animal sections of the skin showed under the microscope enormous dilatation of the sebaceous follicle, with destruction of their cells, and with inflammation and small abscesses in the substance of the cutis. The hairfollicles were dilated, and there was loss of hair from atrophy of the papillæ, probably from the pressure of the acari which penetrated to their roots. "Thus," says Gruby, "a parasite which exists in man as a physiological condition occasions in the dog a disease of a very grave character."

In the course of the year 1873 three dogs were admitted at different times into the Brown Institution, Nine Elms, suffering from a disease of the skin, which consisted of loss of hair, scaliness, and pustulation somewhat resembling acne, and covering the greater part of the body, especially in the second of the three cases. All three died in a few weeks, in spite of all treatment, in a state of wretchedness and emaciation, apparently accelerated by their inability to keep themselves warm from loss of hair. In the first and third cases a careful post-mortem examination, made by my friend Mr. Duguid, the resident veterinary surgeon, to whose kindness $I$ am indebted for the materials of this paper, showed no disease of any internal organ which would account for death. In the second there was inflammation of a few inches of the small intestine, whose origin was not very clear, but was apparently quite unconnected with the skin affection. The third dog died of gradual emaciation while under treatment with sulphur ointment and apparently improving. This dog, a piece of whose skin is before you, was in parts quite hairless, and covered on the back with crusts and scales of pus and exudation from the eczema caused by the irritation of the acari and the dog's scratching. He shivered continually though it was summer time, and seemed quite unable to keep himself warm.

Other dogs which were kept in the kennel with the second dog caught the disease from him, and had to be killed eventually. In the pustules with which this dog was studded acari were found in different stages of development, as well as ova, and full-grown acari with six and eight legs 
respectively. The perfect animals in every respect resemble those of man. Pieces of skin were taken from each animal soon after death, and after hardening were examined microscopically.

All the three cases resembled one another in the enormous number of acari present, dilating the hair-follicles and filling the sebaceous glands, so as completely to destroy their secreting cells. The acari were found at all depths, both in the hair-follicles and the sebaceous glands. In all three cases inflammatory changes, of greater or less extent, were found in the cutis, arising from the irritation of the acari and the scratching of the dogs. These consisted of a small-celled growth around the blood-vessels in the papillæ and the upper part of the cutis, and of nodules of a new formation in the neighbourhood of the affected hair-follicles and sebaceous glands, whose size bore some relation to the extent to which the latter were diseased. There was also more pigment than usual in the lower layer of cells of the rete mucosum. The hairs were generally entirely lost, their papillæ atrophied, and even the root sheaths of their follicles in many instances reduced to a sort of thin fibrous layer. These changes will be more clearly comprehended by reference to the drawings of the microscopical preparations which accompany the paper (see Plate VI). In the first case alone nodules were found around the coils of the sweat-glands, deep in the corium, where no acari had penetrated; in fact, these animals appear scarcely ever to enter the sweat-ducts, for I have only seen one instance where such an entrance had apparently occurred. Probably their corkscrew mode of ending on the skin would prevent the acari from penetrating into them. I am inclined, therefore, to attribute this deep-seated inflammation to the irritation set up by the retained secretions of the sweat-ducts from pressure near the surface of the skin. The nodules around the sweat-glands consist (as represented in Plate VI, fig. 4) of a reticulum of nucleated cells as a matrix, with spherical lymph-corpuscles in their meshes (the so-called adenoid tissue), and resemble the similar nodules which occur in 
other parts of the skin in chronic inflammations. Nodules of the same nature occurred just beneath the epidermis in the third case, and in their most advanced stage were found breaking down in their centre so as to form small abscesses, in which numerous acari were present.

With the evidence before us there can therefore be no longer any doubt that the Acarus folliculorum when it occurs in the dog is not by any means a harmless parasite, but, on the contrary, as dangerous to his existence as the Acarus scabiei is to the rabbit, and perhaps in rare cases to very young infants.

From the analogy of the disease in the dog, I cannot help thinking that, after all, some cases of acne in man may be due to the irritation of the acarus. I merely allude to the subject here, and hope to be able to offer some remarks on the subject at a future time.

Mr. Duguid informs me that, as far as he knows, the disease above described has no place in any work on veterinary medicine, and I believe that it has not been described as an independent disease before, for Gruby produced it by inoculation.

In conclusion, I should state that I was led to pay attention to the subject from finding that so many authorities doubted whether the Acarus folliculorum could produce a disease of the skin, and it was not until two of the cases had been examined and preparations made from their skin that I became acquainted with Dr. Gruby's writings, which confirm my own researches and receive confirmation in return from them.

The inquiry has been conducted in the laboratory of the Brown Institution, and I have to offer my best thanks to the authorities of that Institution not only for the opportunities of examining the animals which form the subject of the paper, but for much kind assistance and advice.

Postscript.-Since this paper was read, Prof. Simonds, of the Veterinary College, has called my attention to a paper of his in the 'Royal Agricultural Society's Journal' for 
1865, vol. i. In it he describes a disease in dogs due to the Acarus folliculorum, and gives some directions as to treatment. Prof. Simonds has therefore anticipated a great deal that $I$ have said in my paper, and to him is due the merit of first describing an idiopathic disease arising from this parasite. It is scarcely necessary for me to state that until I received Prof. Simonds' letter I had never met with any reference to his paper, nor had the slightest knowledge of its existence. Others beside myself seem to have similarly overlooked it, probably owing to its publication in a lay journal.-June 14th, 1874. 


\section{DESCRIPTION OF PLATE VI.}

\section{Acarus FolLICULORUM.}

Fra. 1.-Section of skin to show loss of hair and dilatation of the hair-follicles, and sebaceous glands which contain acari, and in several places have quite lost their secreting cells. Some nuclear growth in the cutis, and pigmentation around the hair sheaths. (somewhat oblique section). Hartnack ejepiece III, objective 3.

FIG. 2.-Two sections from parts close to one another. 1. An immensely dilated hair-follicle whose structure is completely destroyed, and which is filled with acari and their débris. Two sebaceous glands open into its upper third, and though not much dilated contain acari. 2. A sebaceous gland dilated, and only filled with the débris of acari. By its side a hair passes up from a follicle which is still intact. Numerous nuclei in surrounding tissues. Hartnack eyepiece III, objective 4.

FIG. 3.-A much dilated hair-follicle with atrophied sheath and papilla. To show the acari highly magnified. Hartnack III, objective 7.

FrG. 4.-Several sweat-ducts cut transversely and obliquely (part of the coils of a gland). A nodule of inflammatory tissue (lymphatic reticulum, see p. 243) is seen filling a large part of the field. At its edges the reticulum, with lymph-corpuscles, is clearly seen, but towards the centre it becomes indistinct, and only the cells can be made out. In a further stage it would constitute a microscopic abscess. A blood-vessel (vein) is seen in section, and a capillary in its length in the nodule. The single layer of epithelium in the sweat-ducts, and the muscular fibres in their walls, are worthy of notice, as a similar arrangement occurs in many of the sweatducts and glands of man. This fact had been observed by Sharpey, Klein, and others, some time ago, but Prof. W. Krause ('Centralblatt für die Med. Wissenschaften,' 1873, No. 52, s. 818) describes it as a new discovery. Hartnack III, objective 7. 
Plate V1.

Fig.].

Med. Chir.Trans. Vol LVII
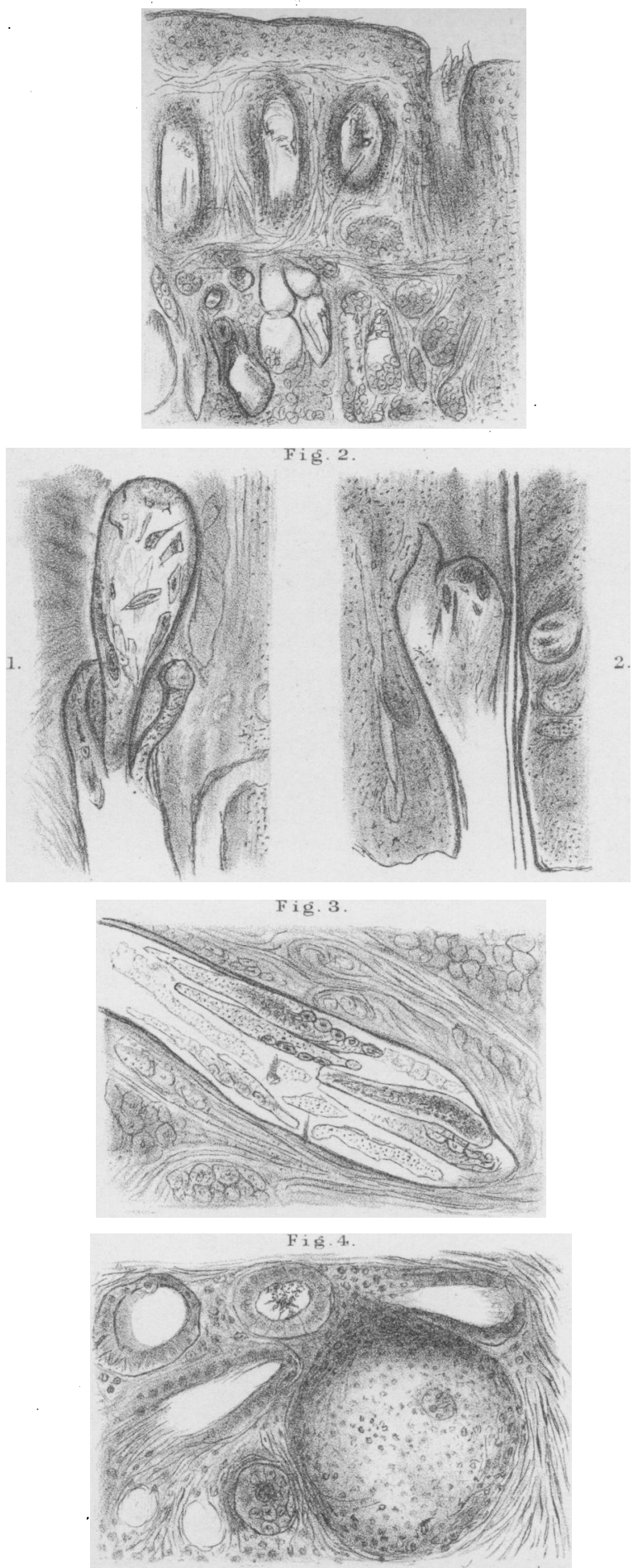